\title{
Aggressive chemotherapy in frail patients with diffuse large B-cell lymphoma: The role of pegylated liposomal doxorubicin
}

\author{
Agustin Avilés, Natividad Neri, María Jesús Nambo, J udith Huerta-Guzmán \\ Oncology Research Unit, Department of Hematology, Oncology Hospital, National Medical Center, IMSS, México, D.F. \\ Mexico
}

Correspondence: Agustin Avilés. Address: Plaza Luis Cabrera 5-502, Colonia Roma, 06700, México, D. F. Mexico. Telephone: 52-555-6276-959. E-mail: agustin.aviles@imss.gob.mx

Received: March 18, 2012

Accepted: May 1, 2012

Published: June 1, 2012

DOI : $10.5430 /$ jhm.v2n2p5

URL: http://dx.doi.org/10.5430/jhm.v2n2p5

\section{Abstract}

Background: Older patients with cardiac problems and diagnosis of diffuse large B-cell lymphoma generally are treated with reduced-dose chemotherapy and anthracyclines, the best drug in this malignancy, generally is omitted. Thus, survival is very poor in this setting of patients ( $<20 \%$ at 3 years). Pegylated liposomal doxorubicin (PLD) has been showed clinical activity in younger patients and without excessive cardiac toxicity.

Methods: Thus, we began an open label in 69 frail patients (Age >65 years, and with diagnosis of cardiac abnormalities), employed a CHOP-like-regimen, with PLD, 30mg/ $\mathrm{m}^{2}$, instead of doxorubicin. Sixty-nine patients were enrolled, in intent to treat analysis all were available for efficacy and toxicity.

Results: Complete response was achieved in 52 cases (72\%). Three patients were excluded for non-hematological toxicity, and 9 patients relapsed, thus with a median follow-up of 73 months (Range 64 to 110 months), actuarial curves at 5-years showed that relapse free survival was 78\% [95\% confidence interval (CI): 69\% to 85\%] and overall survival was $79 \%$ (95\% CI: $71 \%$ to $85 \%$ ). Although severe granulocytopenia was observed in $5.6 \%$ of cycles, no death was observed. Two patients die secondary to myocardial ischemia and 10 patients worsened the left ejection ventricular function, but only 3 developed clinical dates of congestive heart failure.

Conclusions: We considered that the use of PLD is an effective and safe drug in the treatment of these special setting of patients with the end-point of treatment is cure.

\section{Key words}

Non-Hodgkin's lymphoma, Chemotherapy, Pegylated liposomal doxorubicin, Cardic toxicity

\section{I ntroduction}

Anthracycline based-chemotherapy are the standard treatment for patients with diffuse large B-cell lymphoma (DLBCL) which is the most frequent type of non-Hodgkin's lymphoma. However, physicians are often reluctant to give such treatment to many patients with preexisting cardiac dysfunction, older patients ( $>65$ years), coexisting diseases, or poor performance status ${ }^{[1]}$. Thus, about $40 \%$ of patients with diagnosis of DLBCL could not be treated with an adequate 
regimen and the outcome is very poor. Taking in consideration that DLBCL is a potentially curative disease, management of therapy-related adverse events became a major task. Thus, alternative options are necessary in these patients ${ }^{[2]}$.

The introduction of liposomal and pegylated liposomal anthracyclines open a new options in treatment of this setting of patients because these drugs showed similar antitumoral activity and reduced cardiac toxicity ${ }^{[3-18]}$.

In our institution we developed a program to evaluate the risk of cardiac toxicity secondary to anthracyclines in patients with Hodgkin's lymphoma and non-Hodgkin's lymphoma and we have records of all patients whose received anthracyclines in the last 25 years ${ }^{[19,20]}$. Pegylated liposome doxorubicin (PLD) was introduced in our institution in 1999 and we performed a small clinical study of PLD in younger patients with DLBCL and we proved that PLD retain antitumor activity, without cardiac toxicity, because at 10 years, $50 \%$ of the patients are alive, with normal cardiac function ${ }^{[21]}$.

Thus, we began an open label clinical trial employed PDL in frail patients, who were not candidates to received conventional doses of doxorubicin; they were treated with a CHOP-like regimen with PDL instead of doxorubicin. The goals of the study were to assess if frail patients can be treated with aggressive chemotherapy without excessive risk, including cardiac toxicity and proven efficacy in these setting of patients.

\section{Patients and methods}

From January 2001 to December 2010, previously untreated patients with histologically confirmed diagnosis of diffuse large B-cell lymphoma, stage II to IV, high-or high-intermediate clinical risk according to the International Prognostic Index, no gender differences, performance status $\leq 3$ according to the ECOG classification with a least one of the following clinical risk: Age $>65$ years with not upper limit, presence of cardiac risk factors: High blood pressure, ischemic cardiopathy, cardiac arrythmias, abnormal left ventricular function measured by radionuclide angiogragphy (RA) and echocardiogram $<50 \%$, without clinical evidence of congestive heart failure according to the New York criteria.

This was a prospective, open label, clinical study including consecutive patients and was carried out in the Oncology Hospital, National Medical Center, IMSS, which is a tertiary reference center and has a coverage population of $31,000,000$. The study was approve by the Ethical and Scientific Committee of our Institution; and each patient have written consent to participate in the study.

\section{Staging}

Before the beginning of the treatment, patients were carefully evaluated with clinical history, physical examination, complete blood counts, serum chemistry, and lactic dehidrogenase, computed tomography of thorax, abdomen and pelvis, tests for immunodeficiency virus and hepatitis B and C; aspirate and bone marrow biopsy. Cardiac evaluation includes cardiac exploration, RA and echocardiogram. Four weeks after completion of the planned treatment, each patient was carefully restaged. Subsequent follow-up was performed every 6 months the first three years and every year until relapse, death or last follow-up (July-December 2011). Cardiac evaluation was performed repeat RA and echocardiogram every 6 months.

\section{Treatment}

PLD $30 \mathrm{mg} / \mathrm{m}^{2}$, dissolved in $250 \mathrm{~mL}$ of glucose water solution $5 \%$ and infused in 60 ', was given on day 1 in combination with cyclophosphamide $750 \mathrm{mg} / \mathrm{m}^{2}$, vincristine $2 \mathrm{mg}$ standard dose and prednisone $60 \mathrm{mg} / \mathrm{m}^{2}$, every 21 days for 6 courses. The choice to adopt the dosage of $30 \mathrm{mg} / \mathrm{m}^{2}$ of PLD was based in the results of our previous study ${ }^{[21]}$. Antiemetics were administered to avoid the presence of severe nausea/vomiting. Granulocyte colony-stimulating factor (G-CSF) was not allowed during the first course of chemotherapy but could be used in later cycles in case of febrile granulocytopenia. If grade 3-4 of hematological toxicity developed the next cycle was delayed until hematological recovery. Cycles could also 
be delayed if severe non-hematological toxicities occurred, especially grade 2-4 palmo-plantar erythro dysesthesia. Acute cardiac toxicity, as CHF, was considered as cause to stop the treatment.

\section{Response criteria}

After chemotherapy, the patient was carefully restaged with the same clinical, laboratory and radiological initial studies. Response criteria was employed the International criteria for DLBCL ${ }^{[22]}$.

\section{Statistical analysis}

The main parameters analyzed were treatment toxicity and disease response (Complete response rate, overall response). Secondary end-points analyzed were overall survival (OS), defines as the interval from the first day of treatment until death or last follow-up, progression-free survival (PFS) defined as the interval from the achievement of CR until relapse or progression or death or last follow-up. Survival calculation was made by the Kaplan-Meier method and the closing day for analysis was December 31, 2011.

\section{Results}

Table 1 showed the main clinical and laboratory characteristics. As expected, older, advance disease, higher clinical risks, presence of bulky disease were observed. All patients present at least two cardiac risk factors. Sixteen patients showed an abnormal LEVF, but without clinical manifestations of CHF and were included in the study. In an intent to-treat analysis all patients were evaluable for efficacy and toxicity. All patients completed the programmed chemotherapy.

Table 1. Demographic characteristics

\begin{tabular}{|c|c|}
\hline & No. \\
\hline No. & 69 \\
\hline Age (Years): Median & 71.7 \\
\hline Range & $65-80$ \\
\hline Gender: Male/female & $35 / 34$ \\
\hline Stage III & 11 \\
\hline IV & 58 \\
\hline IPI: High-intermediate & 12 \\
\hline High & 57 \\
\hline \multicolumn{2}{|l|}{ Extranodal sites* } \\
\hline Liver & 28 \\
\hline Spleen & 17 \\
\hline Bone marrow & 16 \\
\hline Stomach & 14 \\
\hline Lung & 7 \\
\hline Bulky disease (Tumor mass $>10 \mathrm{~cm}$ ) & 40 \\
\hline Beta 2 microglobulin $(>2 \mathrm{~N})$ & 44 \\
\hline \multicolumn{2}{|l|}{ Comorbidities $(*)$} \\
\hline Diabetes mellitus & 34 \\
\hline Hypertension & 52 \\
\hline Ischemic cardiopathy & 11 \\
\hline Cardiac arrhythmia & 6 \\
\hline Abnormal left ventricular ejection fraction & 16 \\
\hline Stroke smoking ( $>20$ cigarretes/day) & 31 \\
\hline
\end{tabular}

Complete response was achieved in 50 cases (72\%). Three patients were retired from the study one developed severe hematological toxicity; and two patients present severe palmo plantar erythrodisestesias and refused to continue with the 
same regimen. They were treated with escalated CEOP (Epirubicine instead of PLD) and achieved CR. At this time, 9 patients relapsed; all were treated with palliative therapy. Two patients developed a fatal cardiac event; both suffer a myocardial infarctation and die. Furthermore, 13 patients die secondary to tumor progression. Thus, actuarial curves at 5-years, showed that RFS were $78 \%$ [95 \% Confidence interval (CI): $69 \%$ to $85 \%$ ] and overall survival was $79 \%$ (95\% CI: $71 \%$ to $85 \%$ ).

Table 2 shown the acute toxicities, granulocytopenia grade III and IV were the most frequent event, and 14 patients developed infection-related granulocytopenia; all were treated with broad spectrum antibiotics and G-CSF; no death related infection were observed.

Table 2. Toxicity

\begin{tabular}{lll}
\hline No. patients & $\mathbf{6 9}$ & \\
\hline No. cycles & 369 & Grade III and IV \\
Hematological & Grade I and II & 0 \\
Anemia & 10 & 21 \\
Granulocytopenia & 74 & 14 \\
Infection-related granulocytopenia & 0 & 1 \\
Thrombocytopenia & 23 & \\
Death-related & 0 & 5 \\
Non-hematological & & 0 \\
Nausea/vomiting & 6 & 0 \\
Diarrhea & 5 & 3 \\
Mucositis & 3 & \\
Palmo-palmar erythrodisestesia & 23 & \\
\hline
\end{tabular}

Ten patients worsened the LEVF who diminished $>10 \%$; however, only one patient developed clinical dates of CHF and need treatment. Six patients that have abnormal LEVF before treatment, return to normal values 5 to 11 months after treatment. No increase in cardiac arrhythmias was observed. Patients with hypertension remain stable, under different drugs, no worsened was observed, and until now no evidence of acute ischemic damage was observed. As mentioned, two patients developed acute myocardial infarctation and died, both were female, age 83 and 76 years and both have antecedents of ischemic disease.

\section{Discussion}

Cardiac toxicity is a well-recognized complication relate to treatment with anthracyclines, however, anthracyclines containing combination chemotherapy can obtain objective responses in $50 \%-8 \%$ of patients with aggressive lymphoma; and until now the use of these type of therapy remain as the gold-standard treatment. More or less strategic selection criteria undoubtedly influence these results; for instance, with similar protocols treatment related deaths occur in 0 to $24 \%$ of cases, reflecting the inclusion of fairly patients. Among the toxicity that can influence on the poor tolerance of these patients.

Cardiac toxicity and granulocytopenia-related infection are probably the most relevant ${ }^{[1-5]}$. Thus, most studies refused to included patients with poor prognostic factors (Elderly, comorbodities, and patients with antecedents of cardiac damage). But, it is evident that these patients can not be treated with palliative attempts, because curative regimens are available for non-Hodgkin's lymphoma. Thus, the treatment of fairly patients will be considered as a curative schedule when it is possible. 
The use of G-CSF, have been seen proved to reduce granulocytopenia-related infection and death-related to these complications ${ }^{[23]}$. Also the introduction of most effective broad-spectrum antibiotic and supportive care to infected patients have been seen contributed to improve tolerance to aggressive chemotherapy.

Considerable research has been undertaken to reduce its associated cardiac toxicity; and currently available for this purpose as the use of dexrozaxane, an iron-quelating agents, has shown that reduce the cardiac toxicity associated to doxorubicin. However, protection is not complete, and its use is associated with increased myelotoxicity that can be severe. The administration of conventional doxorubicin as a continuous infusion has been reported to be less cardiotoxic. However, this schedule is cumbersone and required a central venous catheter, with poses the additional catheter-related risk. Finally, the introduction of liposomal and pegylated liposomal (PLD), has been demonstrate that retain clinical efficacy and reduced acute cardiac toxicity ${ }^{[3,6-10,12,14]}$.

PLD have been extensively employed in some non-hematological neoplasm as breast cancer, with similar results in CR rate and OS to conventional doxorubicin ${ }^{[11,15]}$. But, most of these studies did not have a longer follow-up and only analyzed the presence of acute cardiac toxicity around the treatment and for $<2$ years of follow-up.

In the current study, we addressed the question if substitution of conventional doxorubicin is a feasible and therapeutic option in patients with contraindication for anthracyclines-based treatment and to evaluate the presence of late cardiac toxicity taking in consideration that cardiac toxicity is most frequent after 5 years of the administration ${ }^{[16,17]}$.

The complete response rate (72\%) were similar to younger patients treated with standard chemotherapy; and the outcome showed that $\%$ are alive at $>5$ years and probably could be considered cured. Thus, the use of PLD instead of doxorubicin retain the effectiveness again non-Hodgkin's lymphoma without excessive toxicity. Although severe granulocytopenia was observed in the $3.7 \%$ of the cycles, the early use ( $<48$ hours) of broad spectrum antibiotics, G-CSF, and intensive support care limited the severity of this problem and no death-related granulocytopenia were observed in this study. Palmo-planta erytrhodisistesias and mucositis were common, but were mild and delay in treatment was minimal (Range 3 to days, median 5.3 days); because we limited to $30 \mathrm{mg} / \mathrm{m}^{2}$ the use of PLD, based in our previous study.

Cardiac toxicity was frequent and at 10 years of follow-up, 10 patients (15\%) showed abnormalities in ventricular function with alterations in LEVF and short fraction on echocardiogram, but only 3 cases developed clinical manifestations of CHF or myocardial damage that in two cases were lethal. The other patients are controlled with medication and were an good quality of life, according to yours age, Thus, taking in consideration that $85 \%$ of patients did not developed clinical or laboratory abnormalities, we can consider that the use of PLD is safely and effective in fairly patients with DLBCL even in patients that showed preexisting cardiac impairment, older and/or poor performance status and that in this condition are excluded for aggressive treatment with curative attempt. We can not compare our results with other studies, because follow-up was very short ( $<2$ years) and cardiac abnormalities can not be observed.

Based in our results we can recommend the use of PLD instead of conventional anthracyclines in impairment patients with DLBCL because clearly this drug is effective and safe in this special setting of patients.

\section{Conflict of interest}

The authors declare that there is no conflict of interest statement.

\section{References}

[1] Ng AK, LaCase A, Travis LB.:Long-term complications of lymphoma and its treatment. J Clin Oncol 2011;29:1885-93. PMid: 21483015 http://dx.doi.org/10.1200/JCO.2010.32.8427

[2] Monsuez JJ, Charniot JC, Vignat N, Artigio JI.: Cardiac-side effects of cancer chemotherapy. Int J Cardiol 2010;144:3-15. PMid: 20399520 http://dx.doi.org/10.1016/j.ijcard.2010.03.003 
[3] Solomon R, Gabizon AA.: Clinical pharmacology of liposomal anthracyclines. Focus on pegylated liposomal dorxorubicin. Clin Lymph Myeloma 2008;8:21-32. http://dx.doi.org/10.3816/CLM.2008.n.001

[4] Martino R, Perea G, Caballero MD, Mateos MV, Ribera JM, Perez de Oteyza J, et al.: Cyclophosphamide, pegylated liposomal doxorubicin and prednisone (CCOP) in elderly patients with diffuse large B-cell lymphoma. Haematologica 2002;87:822-27. PMid:12161358

[5] Hunalt-Berger M, Leguay T, Thomas X, Legman O, Huguet F, et al.: A randomized study of pegylated liposomal doxorubicin versus continuos-infusion doxorubicin in elderly patients with acute lymphoblastic leukemia. Haematologica 2011;96:245-52. PMid: 20971822 http://dx.doi.org/10.3324/haematol.2010.027862

[6] Drutgan ST, Keating GM. Pegylated liposomal doxorubicin. Drugs 2011;71:2531-38. PMid: 22141391

[7] Ewer MS, Mantin FJ, Henderson IC, Shapiro CL, Benjamin RS, Gabizon AA.: Cardiac safety of liposomal anthracyclines. Sem Oncol 2004;31 (Suppl 3): 161-81. PMid: 15717742 http://dx.doi.org/10.1053/j.seminoncol.2004.08.006

[8] Shi Y, Moon M, Dawood S, McManus B, Liu II.: Mechanisms and management of doxorubicin cartdiotoxicity. Herz 2011;36:296-305. PMid: 21656050 http://dx.doi.org/10.1007/s00059-011-3470-3

[9] Schmidt CJ, Dietrich S, Ho AD, Witzens-Haring M. Replacement of conventional doxorubicin by pegylated liposomal doxorubicin is a safe and effective alternative in the treatment of non-Hodgkin's lymphoma patients with cardiac risk factors. Ann Hematol 2012;91:391-97. PMid: 21850390

[10] Shah J, Orlowsky RZ, Thoma SK. Role of combination bortezomib and pegylated liposomal doxorubicin in the management of relapsed and/or/ refractory multiple myeloma. Ther Clin Risk Manag 2009;5:151-58.

[11] Healey-Bird BR, Swain SM: Cardiac toxicity in breast cancer survivors. Review of potential cardiac problems. Clin Cancer Res 2008;14:150-44.

[12] Albini A, Perresi G, Donatelli F, Cammaroto R, DeFlora S, Noonan DM.: Cardiotoxicity of anticancer drugs. J Nat Cancer Inst 2010;102:14-25. PMid: 20007921 http://dx.doi.org/10.1093/jnci/djp440

[13] Senkus E, Jassem J. Cardiovascular effects of systemic cancer treatment. Cancer Treat Rev 2011;37:300-11. PMid: 21126826 http://dx.doi.org/10.1016/j.ctrv.2010.11.001

[14] Safra T.: Cardiac safety of liposomal anthracyclines. The Oncologist 2003; 8 (Suppl 2):17-24.

[15] VonMehren M, Schilder RJ, Cheng JD, Temmer E, Cardoso TM, Rensh FG et al.: A phase I study of the safety and pharmacokinetic of combination with pegylated liposomal doxorubicin in patients with advanced malignancies. Ann Oncol 2008;19:1802-809. PMid:18497430 http://dx.doi.org/10.1093/annonc/mdn363

[16] Verma S, Ewer MS.: Is cardiotoxicity being adequate assessed in current trials of cytotoxic and target agents in breast cancer. Ann Oncol 2011;22:1011-18. PMid:21097988 http://dx.doi.org/10.1093/annonc/mdq607

[17] Sawaya H, Sebak IA, Plana JC et al.: Early detection and prediction of cardiotoxicity in chemotherapy treated patients. Am J Cardiol 2011;107:1375-80. PMid: 21371685 http://dx.doi.org/10.1016/j.amjcard.2011.01.006

[18] Zaja F, Tomadini V, Zaclari A, Lenoci M, Battista M, Molinari AL et al.: CHOP-Rituximab with pegylated liposomal doxorubicin for the treatment of elderly patients with diffuse large B-cell lymphoma. Leuk Lymphoma 2006;47:2174-80. http://dx.doi.org/10.1080/10428190600799946

[19] Avilés A, Diaz-Maqueo JC, Arévila-Ceballos N, García-Fernandez N, Lopez-Vancel D, Torras V.: Valoración de la función ventricular en pacientes tratados con mitoxantrona y epirubicina. Arch Inst C ardiol Mex 1989;59:615-18. PMid: 2624510

[20] Avilés A, Díaz-Maqueo JC, García EL, Talavera A, Huerta-Guzmán J, Neri N.: Late lethal events in patients with diffuse large B-cell lymphoma. Leuk Lymphoma 2001;42:631-37. http://dx.doi.org/10.3109/10428190109099323

[21] Avilés A, Neri N, Castañeda C, Talavera A, Huerta-Guzmán Gonzalez M.: Pegylated liposomal doxorubicin in combination chemotherapy of previously untreated aggressive diffuse large B-cell lymphoma. Med Oncol 2002;19:55-58. http://dx.doi.org/10.1385/MO:19:1:55

[22] Cheson BD, Pfistner B, Juwecid ME, Gaycoyne RA, Specht L, Horning SJ et al.: Revised response criteria for malignant lymphoma. J Clin Oncol, 2007;25:579-88. PMid: 17242396 http://dx.doi.org/10.1200/JCO.2006.09.2403

[23] Avilés A, Guzmán R, García EL, Talavera A, Díaz-Maqueo JC. Results of a randomized clinical trial of granulocyte colony stimulating factor in patients with infection and severe granulocytopenia. Anticancer Drugs 1996;7:392-96. http://dx.doi.org/10.1097/00001813-199606000-00003 